\title{
Growth of Phytoplankton
}

\author{
Udriste $C^{*}$ and Tevy I \\ Department of Mathematics-Informatics, Faculty of Applied Sciences, Romania
}

Received: 眥 December 21, 2018; Published: 制January 16, 2019

*Corresponding author: Udriste C, Department of Mathematics-Informatics, Faculty of Applied Sciences, Splaiul Independentei 313, Bucharest, 060042, Centenary of Romanian Great Union 1818-2018, Romania

\section{Abstract}

A central problem in biological dynamical systems is to determine the boundaries of evolution. Although this is a general problem, we prefer to give solutions for growth of the phytoplankton. AMS Mathematical Classiftcation: 92D40, 35B36, 35Q92, 37N25.

Keywords: Phytoplankton Dynamical System; Phytoplankton Sub-strate; Phytoplankton Biomass; Intracellular Nutrient Per Biomasss

\section{Introduction}

\section{Phytoplankton Dynamical System}

In the paper of Bernard - Gouze [1] one analyse a model of phytoplankton growth based on the dynamical system

$$
\begin{gathered}
x^{1}(t)=1-x^{1}(t)-\frac{1}{4} x^{1}(t) x^{2}(t), \\
x^{2}(t)=2 x^{2}(t) x^{3}(t)-x^{2}(t), \\
x^{3}(t)=\frac{1}{4} x^{1}(t) \_2 x^{3^{2}}(t),
\end{gathered}
$$

where $x^{1}$ means the substrate, $x^{2}$ is the phytoplankton biomass and $x^{3}$ is the intracellular nutrient per biomass, with the physical domain $R^{3}+: x=\left(x^{1}, x^{2}, x^{3}\right) \geq 0$. The previous dyn $\Sigma$ amical system is non cooperative and has the equilibrium point $1,0, \frac{\sum \sqrt{1}}{2}$ . We introduce the phytoplankton vector field $X=\left(X^{1}, X^{2}, X^{3}\right)$ of components $X^{1}=1-x^{1}-\frac{1}{4} x^{1} x^{2}, X^{2}=2 x^{2} x^{3}-x^{2}, X^{3}=1 x_{4}^{1}-2 x^{3^{2}} 1$ and the maximal field line $\mathrm{x}=\mathrm{x}(\mathrm{t}, \mathrm{x} 0), \mathrm{t} \in \mathrm{I}$, which satisfies the initial condition $\mathrm{x}(\mathrm{t} 0, \mathrm{x} 0)=\mathrm{x} 0$. In order to find bounds for substrate, biomass, and intracellular nutrient per biomass, we use the techniques of optimization developed in our papers [2-6].

\section{Bounds for Phytoplankton Substrate}

We use the following problem: ftnd $\max \mathrm{f}\left(\mathrm{x}_{1}, \mathrm{x}_{2}, \mathrm{x}_{3}\right)=$ $\mathrm{x} 1$ with the restriction $x=x\left(t, x_{0}\right)$. We set the critical point condition $(\nabla f, X)=0$. In this case $\nabla f=(1,0,0)$. It follows the relation $1-x^{1}-\frac{1}{4} x^{1} x^{2}=0$. The convenient solution (critical point) $x^{-}=\left(x^{-1}, x^{-2}, x^{-3}\right)$ must be

$$
\left.x^{-}=^{-} x^{-1} \in[0,1), x^{-2}=\frac{4\left(1 \_-1\right.}{x^{-1}}\right), x^{-1} \geq 0 \Sigma .
$$

The sufficient condition Hess $f(X, X)\left(x^{-}\right)+\left(\nabla f, D_{X} X\right)\left(x^{-}\right)<0$ reduces to $\left(\nabla f, D_{X} X\right)\left(x^{-}\right)<0$ or $1+\frac{x^{-2 \Sigma-}}{4} 1-x^{-1}-\frac{1}{4} x^{-1-2 \Sigma}+\frac{x^{-1}}{4}\left(2 x^{2} x^{3}-x^{-2}\right)>0$.

Since at the critical point we have $x^{-2}=\frac{4\left(1 \_x^{-1}\right)}{x^{-1}}$, the condition goes to $\left(1-x^{-1}\right)\left(2 x^{-3}-1\right)>0$, and the convenient condition is $x^{-1}<1,2 x^{-3}>1$ . Theorem 2.1. Suppose that on a evolution line (field line) it exists a point $\mathrm{x}^{-}$at which we have

$$
\bar{x}^{-1}<1,2 \bar{x}^{-3}>1, \bar{x}^{2}=\frac{4\left(1-\bar{x}^{-1}\right)}{\overline{x^{1}}}
$$

Then the phytoplankton substrate has an upper bound at this point.

\section{Bounds for Phytoplankton Biomass}

Let us use the problem: ftnd max $g\left(x^{1}, x^{2}, x^{3}\right)=x^{2}$ subject to $x=x\left(t, x_{0}\right)$.

Growth of phytoplankton: The critical point condition is $(\nabla g, X)=0$. Since $\nabla g=(0,1,0)$, it follows the relation $2 x^{2} x^{3} x=0$. The convenient solution (critical point) $\bar{x}=$ $\left(\bar{x}^{1}, \bar{x}^{2}, \bar{x}^{3}\right)$ must have $\bar{x}^{3}=1$. The sufficient condition Hess $g(X, X)(\bar{X})+\left(\nabla g, D_{X} X\right)(\bar{X})<0$ reduces to $\left(\nabla g, D_{X} X\right)<0$ or $\bar{x}^{2}\left(2 x^{-3}-1\right)^{2}+2 x^{-2}\left(1 \frac{x}{4}-2 x^{-3}\right)^{2}<0$. Since at the critical point we have , the sufficient condition leads to $\bar{x}^{2}\left(\bar{x}^{-1}-2\right)<0$, i.e., $x^{-1}-2<0$.

Theorem: Suppose that on a evolution line (field line) it exists a point at which we have

$$
\bar{x}^{-1}<2, \bar{x}^{2}>0, \bar{x}^{3}=\frac{1}{2}
$$


then the $x^{2}(t)$ component of the corresponding field line has an upper bound at this point.

In the direct alternative, we build the composite function $\mathrm{g}(\mathrm{x}(\mathrm{t}$, $\mathrm{x} 0)$ ). The condition

$$
\frac{d}{d t} g\left(x\left(t, x_{0}\right)\right)=\frac{\partial \cdot g}{\partial x}\left(x\left(t, x_{0}\right)\right) \frac{d x^{i}}{d t}(t)=0
$$

reduces to $\frac{d x^{2}}{d t}(t)=0$, i.e., $2 x^{2} x^{3}-x^{2}=0$. the convenient solution is $x^{3}=\frac{1}{2}$. The condition

$\frac{d^{2}}{d t^{2}} g\left(x\left(t, x_{0}\right)\right)=\frac{\partial^{2} \cdot g}{\partial x^{i} \partial x^{j}}\left(x\left(t, x_{0}\right)\right) \frac{d x^{i}}{d t}(t)+\frac{d x^{j}}{d t}(t)+\frac{\partial^{2} \cdot g}{\partial x^{i}}\left(x\left(t, x_{0}\right)\right) \frac{d_{2} x^{j}}{d t^{2}}(t)<0$,

becomes $\quad 2 x^{2}(t) \frac{d x^{3}}{d t}(t)<0$, i.e., $x^{2}>0, \frac{1}{4} x^{1}-2 x^{32}<0$. $\quad$ Replacing $x^{3}=\frac{1}{}, 2$ we find $x^{2}>0, x^{1}-2<0$. The same result is obtained as in the previous method.

\section{Bounds for Intracellular Nutrient Per Biomass}

Now the helping problem is: compute max $h\left(x^{1}, x^{2}, x^{3}\right)=x^{3}$ with the restriction $x=x\left(t, x_{0}\right)$.

The critical point condition is $(\nabla h, X)=0$. Since $\Delta \mathrm{h}=$ $\nabla h=(0,0,1)$, it follows the relation $\frac{1}{4} x^{1}-2 x^{32}=0$. The critical point

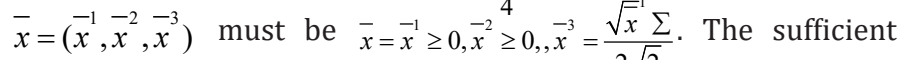
condition Hess $h(X, X)(\bar{x})+\left(\nabla h, D_{X} X\right)(\bar{x})<0$ r $\sqrt{2}$ duces to

ISSN: 2574-1241

DOI: 10.26717/BJSTR.2019.13.002360

Udriste $C$. Biomed J Sci \& Tech Res

This work is licensed under Creative Commons Attribution 4.0 License

Submission Link: https://biomedres.us/submit-manuscript.php $\left(\nabla h, D_{X} X\right)(\bar{x})<0$ or $\frac{1}{4} 1-\bar{x}^{-1}-\frac{1}{4} x^{-1} x^{2}-4 \bar{x}^{-3} \frac{1}{4} \bar{x}^{-1}-2{\overline{x^{3}}}^{2}<0$

Since at the critical point we have $\frac{-3}{x}=\frac{\sqrt{-1}}{2 \sqrt{2}}$ the condition goes to $1-x^{-1}-\frac{1}{4} x^{-1-2} x^{2}<0$, i.e., $1<x^{-1}\left(1+\frac{1}{4} x^{2}\right)$

Theorem: Suppose that on a evolution line (field line) it exists a point

$\bar{x}$ at which we have $1<\bar{x}^{-1}\left(1+\frac{1}{4} x^{2}\right), \bar{x}^{-3}=\frac{\sqrt{x^{-1}}}{2 \sqrt{2}}$. Then the intracellular nutrient per biomass has an upper bound at this point.

\section{References}

1. Bernard O, Gouze JL (2002) Global qualitative description of a class of nonlinear dynamical systems. Artificial Intelligence 136(1): 29-59.

2. Calin O, Udriste C (2014) Geometric Modeling in Probability and Statistics, Springer.

3. Udriste C (1994) Convex Functions and Optimization Methods on Rieman-nian Manifolds, Mathematics and Its Aplications 297, Kluwer Aca- demic Publishers.

4. Udriste C (2000) Geometric Dynamics, Mathematics and Its Aplications 513, Kluwer Academic Publishers 24(2): 313-322.

5. Udriste C, Dogaru O (1991) Extrema conditioned by orbits, in Romanian. Sci Bul. IPB 51: 3-9.

6. Udriste C, Dogaru O, Tevy I (2002) Extrema with Nonholonomic Constraints, Geometry Balkan Press.

$\begin{array}{ll}\text { BIOMEDICAL } & \text { Assets of Publishing with us } \\ \text { RESEARCHES } & \text { - Global archiving of articles } \\ \text { - Immediate, unrestricted online access }\end{array}$

